\section{International Scientific Journal Theoretical \& Applied Science}

Malakhat Soltan Huseynova Doctor of Philosophy in Economics, Associate Professor of the Department "Organization of business and management", Sumgayit State University, Azerbaijan Republic nauka-xxi@mail.ru

Year: 2017 Issue: $06 \quad$ Volume: 50

Published: $30.06 .2017 \quad$ http://T-Science.org

SECTION 19. Management. Marketing. Public administration.

\title{
THE DEVELOPMENT AND IMPROVEMENT OF AGROPROCESSING MARKET MANAGEMENT IN CONDITIONS OF DEEPENING OF MARKET RELATIONS
}

\begin{abstract}
The issues of development and improvement of agroprocessing market management in conditions of deepening market relations are explored in the article. The processes of development of the agrarian sector and the agroprocessing market, the potential for an increase in the volume of production to expand the agro-processing market are analyzed. The main indicators of enterprises engaged in the production of agricultural products in the Republic of Azerbaijan are considered. Indicators of the level of non-self-sufficiency of a number of products in the Republic of Azerbaijan are studied and the necessity of expanding their production and processing for activating the agroprocessing market is justified. The level of dependence of imports on the provision of basic types of industrial products of agroprocessing in the Republic of Azerbaijan is given and the directions and priority tasks for minimizing the level of import dependence on agroprocessing products are examined. Important indicators of the main types of enterprise's products in kind, engaged in the production of agricultural products in the Republic of Azerbaijan, were analyzed and their most important tasks in conditions of deepening market mechanisms are considered.

The results of the development and improvement of the agroprocessing market management in the conditions of deepening market relations are summarized at the end of the article.

Key words: Azerbaijan, agrarian sector, agrarian industry, agroprocessing market development, improvement of agroprocessing market management, efficiency, food security.

Language: Russian

Citation: Huseynova MS (2017) THE DEVELOPMENT AND IMPROVEMENT OF AGROPROCESSING MARKET MANAGEMENT IN CONDITIONS OF DEEPENING OF MARKET RELATIONS. ISJ Theoretical \& Applied Science, 06 (50): 145-151.

Soi: http://s-o-i.org/1.1/TAS-06-50-20 Doi: crossef https://dx.doi.org/10.15863/TAS.2017.06.50.20

\section{РАЗВИТИЕ И СОВЕРШЕНСТВОВАНИЕ УПРАВЛЕНИЕМ РЫНКА АГРОПЕРЕРАБОТКИ В УСЛОВИЯХ УГЛУБЛЕНИЯ РЫНОЧНЫХ ОТНОШЕНИЙ}

Аннотация: В статье исследованы вопросы развития и совершенствования управлением рынка агропереработки в условиях углубления рыночных отнотений. Анализированы процессы развития аграрного сектора и рынка агропереработки, потенциал увеличение объёма производства по расиирению рынка агропереработки. Рассмотрены основные показатели предприятий занятых производством аграрной продукиии в Азербайджанской Республике. Изучены показатели уровня не самообеспеченности ряда продукций в Азербайджанской Республике и обоснована необходимость расширения их производства и переработки для активизации рынка агропереработки. Даны уровень зависимости импорта по обеспечению основными видами промышленной продукции агропереработки в Азербайджанской Республике и рассмотрены направления, приоритетные задачи по минимизации уровня зависимости импорта по продукциям агропереработки. Анализированы важные показатели основных видов продукций предприятия в натуре, занятых производством аграрных продукиий в Азербайджанской Республике и рассмотрены их важнейшие задачи в условиях углубления рыночных механизмов.

В конце статьи обобщень итоги по вопросам развития и совершенствования управлением рынка агропереработки в условиях углубления рыночных отношений.
\end{abstract}


Ключевые слова: Азербайджан, аграрный сектор, аграрный промышленность, развитие рынка агропереработки, совершенствование управления рынка агропереработки, эффективность, продовольственный безопасность.

\section{Introduction}

Азербайджан, после восстановления независимости, должен был решить ряд стратегических задач по созданию новой экономической системы в свете требований рыночных механизмов и рыночных отношений. Среди сложных отраслей национальной экономики особо отличились специфические механизмы, системы деятельности рынка агропереработки, который нуждался практически в создании совершенно нового механизма управления и практичных инструментарий. Дело в том, что при бытности в составе бывшего СССР во всех республиках, в том числе в Азербайджане вопросы регулирования системы управления по рынку агропереработки решались централизовано в Москве, а на местах потребовались чёткое выполнение тех или иных конкретных задач по разнарядкам, планам или отдельным поручениям. Продукции агропереработки могли поступить по указанным потребителям и адресантам из Москвы во всех 15 республиках бывшего СССР и не потребовались дополнительные усилия, работы или формирование специальных структур, механизмов для развития и управления рынка агропереработки. Как известно, в те времена существовала так называемая система кооперативной торговли, которая всюду и во всех регионах республики производила закупки и реализацию всех ассортиментов предприятий агропереработки и практически рынок агропереработки управлялся так называемыми «копторгами» и его центральным управлением, который реализовал функции осуществления государственной политики и разработку практичных механизмов данной сферы. Однако всё это осталось в прошлом, хотя разные подразделения данной системы до сих пор остались действовать, но их деятельность практически потеряла свою значимость и эффективность в условиях новых экономических систем, то есть в системе рыночных отношений. В числе приоритетных задач и проблем по развитию и совершенствованию управлением рынка агропереработки в условиях углубления рыночных отношений в Азербайджане можно выделить следующее:

- в связи с проведением аграрной реформы и земельной реформы в Азербайджане, в стране образовались десятки тысяч частных предпринимателей, фермерских хозяйств, семейных хозяйств и прочих структур в сельских местах, которые в основном занимаются выращиванием

и

реализацией

сельскохозяйственной продукции;

- в регионах страны, в рамках реализации государственных программ по решению социально-экономических проблем и развитию регионов, в основном завершены строительства и ввод в эксплуатацию инфраструктурах объектов, другими словами стабильное обеспечение электрической энергией, природным газом, водой, сельскохозяйственной техникой, минеральными удобрениями, транспортными узлами, современной дорожной инфраструктурой и прочим, которые создают благоприятные условия для развития и совершенствования управлением рынка агропереработки для активного выхода на внешний рынок;

- государство активно поддерживает и стимулирует развитие расширения агроперерабатывающей отрасли, создание прочной материально-технической базы для её развития, построены крупные объекты и заводы по агропереработке сельскохозяйственной продукции - овощей и фруктов, мясомолочных изделий, минеральных вод, соков, вин и прочих;

- в нынешних условиях особые меры принимаются в восстановлении традиционных рынков агропереработки в регионах, в том числе в бывших республиках СССР, особенно в Российской Федерации и его субъектах, где традиционно торговались продукцией агропереработки из Азербайджана и спрос на них всегда был на высоком уровне и продолжает оставаться по сегодняшний день;

- государство в последние годы особое внимание уделяет развитию транспортных узлов и системе логистики, расширению складских помещений, созданию логистического центра в портах Каспийского моря, в том числе в портах традиционных и стратегических партнёров стран по приёму, хранению, транспортировке и реализации продукции переработки, однако все эти работы находятся в стадии развития и пока интенсификация данного процесса требует немалого времени, вложение инвестиционных ресурсов, реагирования множественных организационных и управленческих вопросов;

- в международном морском порту, в Каспийском море, в посёлке Алят создаётся Свободные Торговая Зона, которая будет способствовать расширению логистической возможности страны по движению продукции агропереработки производителей Азербайджана не только на региональном рынке, но и откроет большие перспективы по выходу на внешние 


\begin{tabular}{|c|c|c|c|c|c|c|}
\hline Impact Factor: & $\begin{array}{l}\text { ISRA (India) } \\
\text { ISI (Dubai, UAE } \\
\text { GIF (Australia) } \\
\text { JIF }\end{array}$ & $\begin{array}{l}=1.344 \\
=0.829 \\
=0.564 \\
=1.500\end{array}$ & $\begin{array}{l}\text { SIS (USA) } \\
\text { PИНЦ (Russia) } \\
\text { ESJI (KZ) } \\
\text { SJIF (Morocco) }\end{array}$ & $\begin{array}{l}=0.912 \\
=0.234 \\
=3.860 \\
=\mathbf{2 . 0 3 1}\end{array}$ & $\begin{array}{l}\text { ICV (Poland) } \\
\text { PIF (India) } \\
\text { IBI (India) }\end{array}$ & $\begin{array}{l}=6.630 \\
=1.940 \\
=4.260\end{array}$ \\
\hline
\end{tabular}

зарубежные - международные рынки агропереработки.

\section{Materials and Methods}

Следует подчеркнуть, что вопросы и проблемы развития аграрной переработки и его рынка эффективность системы управления рассмотрены в трудах многих учёных и исследователей. Должны отметить, что эта проблема в нынешних условиях особо настораживает пространство бывшего СССР, так как создание более эффективных методов и системы управления и механизмы развития рынка агропереработки является государственной важной задачей для всех республик выходцев бывшего СССР, в том числе и для Азербайджана, России и прочих. Много учёных и специалистов, да и государственных структур рассматривают целесообразность усиления совместной деятельности этих республик по развитию рынка агропереработки, так как имелись традиционные кооперационные и хозяйственные связи, рынки агропереработки и в современных условиях развития рынка переработки исходя из национальных интересов по обеспечению продовольственной безопасности своих стран. Например, считается, что Агропром Азербайджана может сыграть особую роль в стратегии Российского импротозамещения и сможет способствовать в смягчении антироссийского торгового эмбарго Западного мира. Речь, как о краткосрочном периоде, так и на долгосрочной, учитывая, что созданные в предстоящий период логистической связи между бизнесов двух стран сформируют новые агропромышленные отношения[1]. Более того, в последние годы руководство и правительство Азербайджана последовательно и настойчиво принимает комплексные меры, оказывает государственную поддержку по развитию и совершенствованию управлением рынка агропереработки с дальнейшем выходом национальной продукции на мировые рынки, главным смыслом, которого является брендирование национальных продукций во всех пространства рынка переработки. А.Караваев подчёркивает, что развитие Азербайджанского агробизнеса как раз движется в данном направлении. Еврокомиссия вместе с партнёрами из Минсельхоза Азербайджана начали проект технической помощи «Поддержка электронного сельского хозяйство в Азербайджане». Помимо прочих задач, проект призван разработать регистр хозяйств и ассортимент их продукции[2]. Дело в том, что в Азербайджане за последние годы объем производства сельхозпродукции и особенно продукции агропереработки заметно растёт, производится качественная продукция, предприятия агропереработки оснащаются современными зарубежными оборудованиями, применяются новые методы управления и развивается рынок переработки в стране, создаются прочные базы и почва для активизации выхода на внешний рынок отечественных производителей, компании и фирм. В Таблице 1 даны основные показатели предприятий занятых производством аграрной продукций в Азербайджанской Республике.

Таблица 1

Основные показатели предприятий занятых производством аграрной продукций в Азербайджанской Республике, \%

\begin{tabular}{|c|l|c|c|c|c|c|c|}
\hline п/н & \multicolumn{1}{|c|}{ Показатели } & 2010 & 2011 & 2012 & 2013 & 2014 & 2015 \\
\hline 1 & Число функционирующих предприятий, в том числе: & 409 & 396 & 427 & 439 & 389 & 382 \\
\hline & государственные & 14 & 16 & 17 & 17 & 18 & 18 \\
\cline { 2 - 9 } & негосударственные частных предпринимателей, & 1925 & 2108 & 2575 & 2516 & 2597 & 2547 \\
\hline 2 & $\begin{array}{l}\text { Число } \\
\text { зарегистрировавших производство промышленным } \\
\text { способом }\end{array}$ & & & & & \\
\hline 3 & $\begin{array}{l}\text { Доля сферы в общем объёме промышленной } \\
\text { продукции произведённой в стране, в \% }\end{array}$ & 1,5 & 1,5 & 1,5 & 1,7 & 2,0 & 2,5 \\
\hline 4 & $\begin{array}{l}\text { Доля сферы в общем объёме промышленной } \\
\text { продукции, производимой негосударственным } \\
\text { сектором, в \% }\end{array}$ & 8,6 & 7,5 & 9,3 & 9,1 & 10,2 & 12,6 \\
\hline 5 & Инвестиции в основной капитал, млн. манат & 27,1 & 46,5 & 75,3 & 160,8 & 92,4 & 87,9 \\
\hline 6 & $\begin{array}{l}\text { Доля сферы в общей инвестиции, вложенной в } \\
\text { промышленный сектор страны, в \% }\end{array}$ & 0,63 & 0,87 & 1,2 & 2,1 & 1,2 & 1,0 \\
\hline
\end{tabular}

Примечание: Таблица 1 подготовлено автором на основе материалов Государственного Статистического Комитета Азербайджанской Республики. http://www.azstat.gov.az 
Если проанализировать Таблицу 1, то можно увидеть, что за 2014-2015 годы уменьшилось число функционирующих предприятий, занятых производством аграрной продукции. Доля сферы, в общем объёме произведённой в стране по итогам 2015 года составляет $2,5 \%$. К сожалению, доля сферы в общей инвестиции, вложенной в промышленный сектор страны, тоже находится в тенденции снижении и в 2015 году составил лишь $1 \%$.

Отметим, что в Азербайджане степень самообеспеченности по большинству наименований сельхозпродукции колеблется в пределах 76-98 \%. Государство скупает готовые продукции хозяйство по ценам, выше рыночной, а затем продаёт её своим же азербайджанским перерабатывающим компаниям по субсидируемой цене. Это позволяет, во-первых, найти аграриям средств для расширения производства, а во-вторых, развиться сектору переработки и сопутствующим сферам. В Таблице 2 отражены показатели уровня не самообеспеченности ряд продукций в Азербайджанской Республике.

Таблица 2

Уровень несамообеспеченности ряд продукций в Азербайджанской Республике, \%

\begin{tabular}{|c|l|c|c|c|c|c|c|}
\hline п/н Показатели & 2010 & 2011 & 2012 & 2013 & 2014 & 2015 \\
\hline 1 & Крупы всех видов & 11,3 & 1,4 & 16,6 & 19,3 & 18,2 & 17,9 \\
\hline 2 & Мука всех видов & 95,1 & 84,1 & 94,1 & 93,8 & 94,8 & 95,1 \\
\hline 3 & Макаронные изделия & 72,7 & 63,6 & 70,2 & 52,6 & 58,0 & 53,2 \\
\hline 4 & Растительные масла & 74,3 & 62,3 & 64,8 & 74,9 & 67,0 & 60,5 \\
\hline 5 & Сливочные масла & 50,0 & 50,2 & 50,4 & 50,5 & 51,9 & 69,2 \\
\hline 6 & Сыр всех видов & 85,7 & 86,5 & 88,2 & 80,5 & 80,4 & 84,2 \\
\hline 7 & Чай & 63,2 & 62,1 & 65,6 & 54,7 & 50,7 & 40,2 \\
\hline 8 & Овощные и фруктовые консервы & 91,8 & 87,4 & 90,7 & 90,7 & 91,4 & 87,6 \\
\hline
\end{tabular}

Примечание: Таблица 2 подготовлено автором на основе материалов Государственного Статистического Комитета Азербайджанской Республики. http://www.azstat.gov.az

Исходя из Таблицы 2 можно сделать вывод о том, что в Азербайджане требуется расширение сети переработки аграрных продукций и их рынков по продукциям крупы всех видов, растительные и сливочные масла, чай и другие. Как известно, современная агропереработка сложная многослойная сеть, сочетающая разные компоненты - от инфраструктуры до конкретных субъектов деятельности[3]. В одной из крупных агроцентров Азербайджана - в Западном регионе страны создаются Шамкирский агропарк. В самое ближайшее время там будут открыты сразу несколько перерабатывающих предприятий, причём большая часть инвестиций - $80 \%$ иностранные [4]. С одной стороны государственные поддержки с созданием одновременно благоприятных условий, в том числе налоговых и прочих льгот по развитию рынка агропереработки, его инфраструктуры, логистической сети будут способствовать интенсификации развития в самой системе агропереработки в последующем его рынке, тем самым будут обуславливать совершенствование управления рынками агропереработки исходя из современных тенденций мировых рынков агропереработки и глобальных изменений в мире. Профессора М.Лешева и Е.Гангало считают, что уровень и приоритетные направления государственной поддержки отрасли определяются финансовыми возможностями и текущими задачами аграрных политик разных стран, при этом выделяются некоторые общие характерные черты. Учёт современных тенденций и позитивного опыта государственного регулирования сельского хозяйства и экономически развитых зарубежных странах необходим для совершенствования отечественного механизма государственного регулирования отрасли в условиях политики импортазамещения и наращивания собственного производства сельскохозяйственной продукции[5]. Более того, обеспечение благоприятной условия реализации сельскохозяйственной продукции и в целом продукции агропереработки способствуют расширения их рынков и повышения экспортного потенциала. Реализация потенциальных возможностей экспорта требует формирования соответствующего организационного экономического механизма, способствующего повышению эффективности логистических функций, совершенствования, инфраструктурного обеспечения хозяйственной деятельности в данном направлении[6]. Отметим, что последние годы усиливается тенденция огосударствления сферы агропереработки и в связи с этим нуждается в новых методах и механизмах развитие данной отрасли. 
Необходимо выбрать приоритеты аграрной политики на основе анализа показателей обеспечения и самообеспечения, как критериев достижения генеральной цели[7]. Необходимо устранить такие негативные тенденции, как неустойчивости производственно-хозяйственных связей, ослабление внутреннего продовольственного рынка и серьёзная угроза продовольственной безопасности страны[8]. Более того, требуется расширение инфраструктуры и совершенствование механизма рынков агропереработки. Для обеспечения участников аграрного рынка оперативными и достоверными сведениями необходим соответствующий набор институтов информационной инфраструктуры[9].

Следует подчеркнуть, что в Азербайджане усиливается тенденции по улучшению основных показателей самообеспечения важными видами продукций агропереработки и развитие его рынков. Повышается уровень качества и эффективности деятельности предприятий агропереработки[10]. Проводимые работы по развитию агропереработки и его рынков должны интенсифицироваться в сторону, где необходимо снизить уровень зависимости импорта по обеспечения основными видами промышленной продукции агропереработки в Азербайджанской Республике(см. Таблица 3).

Таблица 3

Уровень зависимости импорта по обеспечения основными видами промышленной продукции агропереработки в Азербайджанской Республике, \%

\begin{tabular}{|c|l|c|c|c|c|c|c|}
\hline & Показатели & 2010 & 2011 & 2012 & 2013 & 2014 & 2015 \\
\hline 1 & Растительные масла & 91,1 & 82,4 & 87,3 & 86,1 & 81,2 & 73,3 \\
\hline 2 & Фруктовые и овощные соки & 48,8 & 35,4 & 30,2 & 19,7 & 19,8 & 22,8 \\
\hline 3 & Фруктовые и овощные консервы & 14,5 & 21,7 & 14,2 & 15,9 & 12,4 & 14,4 \\
\hline 4 & Сливочные масла & 50,0 & 49,8 & 49,6 & 49,9 & 48,2 & 31,5 \\
\hline 5 & Сахар & 42,7 & 40,5 & 34,8 & 29,9 & 27,2 & 37,2 \\
\hline 6 & Чай & 83,9 & 80,6 & 77,6 & 100,7 & 83,6 & 87,6 \\
\hline 7 & Сыр всех видов & 14,3 & 13,5 & 11,8 & 19,9 & 19,6 & 15,8 \\
\hline 8 & Крупа всех видов & 88,7 & 98,6 & 83,5 & 80,8 & 81,9 & 82,1 \\
\hline 9 & Очищенный рис & 87,0 & 86,8 & 87,3 & 85,5 & 91,7 & 90,5 \\
\hline 10 & Сырье для производства сахара & 97,6 & 95,9 & 96,9 & 95,5 & 96,0 & 94,4 \\
\hline
\end{tabular}

Примечание: Таблица 3 подготовлена автором на основе материалов Государственного Статистического Комитета Азербайджанской Республики.http://www.azstat.gov.az.

Как видно из Таблицы 3, Азербайджан, по итогам 2015 года, зависит от импорта по обеспечению основного вида промышленной продукции агропереработки по производству растительных масел - на 73,3 \%, чая - на 87,6 \%, крупы всех видов - на 82,1\%, сырья для производства сахара - на 94,4 \%, очищенного риса - на 90,5 \% и т.д. Стоит обратить внимание на то, что для развития производства и рынка агропереработки по таким продукциям как растительные масла, чай, и сахар в самом Азербайджане имееся огромный неиспользованный потенциал. А выращивание чая и его переработка считается одной из традиционных сфер деятельности в Азербайджане. В связи с определением новейшей задачи и стратегической цели развития аграрного сектора и рынка агропереработки необходимо учитывать возможность развития данной сферы. Профессор Э.Гулиев отмечает, что аграрное развитие и развитие его рынков в Азербайджане перешло на новый этап и превратилось в одно из приоритетных направлений ненефтяного сектора страны[11]. Кроме того, развитие аграрной сферы и агрорынков, рост потенциала её переработки рассматривается, как одно из эффективных направлений диверсификации национальной экономики[12]. Расширение ассортимента экспортноориентировочной продукции агропереработки создало благоприятные условия для развития рынка агропереработки[13]. В Таблице 4 даны показатели основных видов продукции предприятий в натуре, занятых производством аграрных продукций в Азербайджанской Республике. 
Таблица 4 Показатели основных видов продукции предприятий, занятых производством аграрных продукций в Азербайджанской Республике, в натуре

\begin{tabular}{|c|l|c|c|c|c|c|c|}
\hline п/н & \multicolumn{1}{|c|}{ Показатели } & 2010 & 2011 & 2012 & 2013 & 2014 & 2015 \\
\hline 1 & Мясо- всего, тыс. тонн & 243,2 & 253,4 & 272,8 & 273,8 & 278,1 & 285,6 \\
\hline 2 & Колбасные изделия, тонн & 2123 & 2361 & 4029 & 6030 & 6637 & 4970 \\
\hline 3 & $\begin{array}{l}\text { Молоко(уровень жирности 1-3 \%), } \\
\text { тыс. тонн }\end{array}$ & 812,8 & 813,5 & 820,0 & 830,2 & 840,1 & 857,4 \\
\hline 4 & $\begin{array}{l}\text { Молоко(уровень жирности 6-29 \%), } \\
\text { тонн }\end{array}$ & 4230 & 4357 & 4460 & 4559 & 4671 & 5132 \\
\hline 5 & Сыр и творог, тонн & 43340 & 44293 & 45142 & 47316 & 48046 & 48494 \\
\hline 6 & Сливочные масла, тыс. тонн & 20,9 & 21,1 & 21,8 & 21,9 & 23,4 & 23,9 \\
\hline 7 & Растительные масла, тыс. тонн & 88,7 & 80,0 & 99,8 & 100,2 & 106,9 & 106,7 \\
\hline 8 & Сахар, тыс. тонн & 335,5 & 334,7 & 355,7 & 423,1 & 410,10 & 335,6 \\
\hline 9 & Мука, тыс. тонн & 1320 & 1328 & 1381 & 1438 & 1476 & 1507 \\
\hline 10 & Натуральный чай, тыс. тонн. & 10,9 & 11,0 & 10,7 & 7,5 & 8,0 & 6,2 \\
\hline
\end{tabular}

Примечание: Таблица 4 подготовлено автором на основе материалов Государственного Статистического Комитета Азербайджанской Республики. http://www.azstat.gov.az

Анализ Таблицы 4 даёт основания отметить, что за последние 10 лет объём производства мяса и молока особо не увеличился, а объём производства колбасных изделий в 2015 году по отношению к 2014 году снизился. Объём производства сливочных масел за последние 10 лет практически находится на одинаковом уровне, с не большим ростом 2014-2015 годах и прочее.

\section{Conclusion}

В итоге, можно резюмировать, что развитие аграрного сектора и рынка переработки в Азербайджане, в условиях углубления рыночных отношений находится в процессе разработки и осуществления новейших механизмов с целью достижения максимального совершенствования управления рынком агропереработки в ближайшей перспективе и т.д.

\section{References:}

1. (2017) Agroprom Azerbaydzhana v strategii rossiyskogo improtozameshcheniya. Informatsionno-Analiticheskiy Tsentr. Available: http://www.ia-centr.ru. (Accessed: 10.06.2017).

2. Aleksandr Karavayev Azerbaydzhanskiye brendy gotovyatsya $\mathrm{k}$ vykhodu na mirovoy rynok. Available: http://www.1news.az. (Accessed: 10.06.2017).

3. (2017) Uspekh novoy politiki v sel'skom proizvodstve zavisit ot sochetaniya neskol'kikh komponentov. «Sdelano v Azerbaydzhane» ili AzeriSunrise.

Available: http://www.caspianagro.az.

(Accessed: 10.06.2017).

4. (2017) Azerbaydzhan pochti izbavilsya ot produktovoy zavisimosti. Available: http://www.casp-news.ru. 10.06.2017).

5. Lesheva MG, Gangalo YV (2016) Gosudarstvennoye regulirovaniye agrarnogo sektora ekonomiki: opyt zarubezhnykh stran//Zhurnal «Ekonomika sel'skogo khozyaystva Rossii», vypusk12, №16, 2016.- p. 90-96.

6. Alpatov A, Osipov A, Sidorenko O, Zavgorodneva O, Fedyushin D (2017) Rossiyskiy eksport zerna i yego infrastrukturnoye obespecheniye//Zhurnal «Ekonomika sel'skogo khozyaystva Rossii», vypusk1, №4, 2017.- p. 18-25.

7. Zhogoleva YY (1997) Razrabotka prioritetov agrarnoy politik Rossii. Diss. d-ra ekon. nauk. Moskva, 1997.-254 p. 
\begin{tabular}{l|lrl|l|ll} 
& ISRA (India) & $=\mathbf{1 . 3 4 4}$ & SIS (USA) & $=\mathbf{0 . 9 1 2}$ & ICV (Poland) & $=\mathbf{6 . 6 3 0}$ \\
Impact Factor: & ISI (Dubai, UAE) $=\mathbf{0 . 8 2 9}$ & PUHL (Russia) $=\mathbf{0 . 2 3 4}$ & PIF (India) & $=\mathbf{1 . 9 4 0}$ \\
& GIF (Australia) & $\mathbf{0 . 5 6 4}$ & ESJI (KZ) & $=3.860$ & IBI (India) & $=\mathbf{4 . 2 6 0}$ \\
& JIF & $\mathbf{1 . 5 0 0}$ & SJIF (Morocco) & $=\mathbf{2 . 0 3 1}$ & & \\
\hline
\end{tabular}

8. Serdyukova LV (2002) Formirovaniye i razvitiye rynka agrarnykh produktov na regional'nom urovne: $\mathrm{Na}$ primere Kurskoy oblasti. Diss. kand. ekon. nauk. Yekaterenburg, 2002.-212 p.

9. Shumakova OV (2004) Formirovaniye informatsionnoy infrastruktury rynka agrarnoy produktsii: $\mathrm{Na}$ materialakh Omskoy oblasti. Diss. kand. ekon. nauk. Omsk, 2004.-196 p.

10. Fikretzade F, Abbasov E (2014) Voprosy povysheniya konkurentosposobnosti pererabatyvayushchey sfery i sovershenstvovaniye yeyo integratsii $\mathrm{s}$ sel'skokhozyaystvennym proizvodstvom v Azerbaydzhane//Azerbaijan Journal of
Economics and Social Studies. Number 1, Volume 1, 2014.-P. 34-45.

11. Guliyev E (2017) Agrarnoye razvitiye perekhodit na novyy etap. Available: http://www.azerbaijan-news.az. (Accessed: 10.06.2017).

12. (2017) Razvitiye agrarnogo sektora i prodovol'stvennoy bezopasnosti. Available: http://www.azerbaijans.com. (Accessed: 10.06.2017).

13. (2015) Spravka po agrarnoy promyshlennosti. Ministerstvo ekonomiki i promyshlennosti Azerbaydzhanskoy Respubliki. Baku, 2015. Available: http://www.senaye.gov.az. (Accessed: 10.06.2017). 